TITLE:

\title{
Probing biopolymer conformation by metallization with noble metals
}

AUTHOR(S):

Chen, Ning; Zinchenko, Anatoly A; Yoshikawa, Kenichi

\section{CITATION:}

Chen, Ning ...[et al]. Probing biopolymer conformation by metallization with noble metals. Nanotechnology 2006, 17(20): 5224-5232

\section{ISSUE DATE:}

2006-10

URL:

http://hdl.handle.net/2433/49167

\section{RIGHT:}

(C) Institute of Physics and IOP Publishing Limited 2006.; This is not the published version. Please cite only the published version.; この論文は 出版社版でありません。引用の際には出版社版をご確認ご利用くださ い。 


\title{
Probing Biopolymer Conformation by Metallization with Noble
}

\section{Metals}

\author{
Ning Chen, Anatoly A. Zinchenko, ${ }^{*}$ Kenichi Yoshikawa \\ Department of Physics, Graduate School of Science, Kyoto University, Sakyo-ku, Kyoto 608-8501, \\ Japan, and Spatio-Temporal Order project, ICORP, JST, Japan \\ e-mail:zinchenko@chem.scphys.kyoto-u.ac.jp
}

\begin{abstract}
We propose a novel method for the simple visual (colorimetric) and spectroscopic monitoring of the conformational state of a biopolymer. We present an experimental example of the detection of the change in the conformation of a giant DNA molecule. This methodology is based on the difference in the manner of metallization with noble metals on a polymer scaffold depending on its conformation. Spectroscopic analysis of the metallization of DNA by metallic silver or gold provides information on the critical concentration of DNA binder, at which the folding transition from the elongated into the compact state occurs, together with the dimension and morphology of a compact DNA condensate. This method may be suitable for use in a rapid screening procedure for the high-throughput analysis of large chemical libraries to evaluate their ability to induce DNA compaction, protein folding and similar important processes.
\end{abstract}

\section{Introduction}

While polymers are well known to play a critical role in the formation and fabrication of noble-metal nanostructures, ${ }^{1-5}$ little is known about the use of DNA chain templates in such processes. Most current studies on the metallization of DNA have been limited to short DNA fragments of less than several kilo base pairs. ${ }^{6-8}$ As a well-known example, the use of short DNA oligomers for the controlled aggregation of metal nanoparticles has been developed by Mirkin and colleagues, ${ }^{6,7}$ who have demonstrated several successful applications of oligonucleotide-conjugated gold nanoparticles for analytical and biomedical purposes. ${ }^{9-11}$ Indeed, the outstanding optical and electronic properties 
of nanosized metal structures ${ }^{12}$ make them prospective candidates for use in analytical protocols and for the preparation of new smart materials. On the other hand, the template method for preparing metal nanowires based on long DNA chains was proposed almost a decade ago along with the use of other polyelectrolytes, ${ }^{14-16}$ and the deposition of different metals on DNA chains using various approaches has been reported since then. ${ }^{17-25}$ It is now well established that when in the form of an unfolded or elongated chain, metallization of DNA by metals such as $\mathrm{Au}, \mathrm{Cu}, \mathrm{Pt}$, etc. leads to the formation of metal nanoparticles on a DNA chain scaffold ${ }^{26-32}$ and such metallization is a promising method for the fabrication of molecular nanowires. ${ }^{33-34}$ DNA chain template metallization is expected to have potential applications beyond the preparation of conductive nanowires. For example, it was recently shown that a network of long DNAs can control the morphology of silver nanoparticles to be spherical or elongated depending on the density of the DNA network. ${ }^{35}$

On the other hand, it has been well established that DNA chains larger than several tens of kilobase pairs undergo a large discrete transition from a disordered coil state into an ordered compact state, ${ }^{36}$ while this abrupt nature of the transition vanishes for DNA molecules shorter than on the order of a few kilobase pairs. ${ }^{36}$ Thus, the folding transition of giant DNA molecules is different from that of short DNAs. Recently, using giant DNA larger than $100 \mathrm{kbp}$ we demonstrated that the metallization of compact DNA chains proceeds through a process that is significantly different from the metallization of elongated chains: compact condensates of DNA serve as toroidal templates for the formation of silver nanorings during silver metal deposition. ${ }^{37}$ This difference in the process of silver metal deposition may be useful for the facile monitoring of changes in the conformation of DNA chains and even for probing the final geometry of a DNA condensate. Furthermore, this approach may provide a simple method for monitoring other related processes such as the conformational transitions of proteins during folding. In this report, we describe an analytical approach for probing the DNA conformation and for detecting the DNA folding transition point through the deposition of silver and gold on a DNA chain scaffold.

\section{Experimental part.}


Materials. Bacteriophage T4 DNA (ca. 166,000 base pairs, Nippon Gene Co., LTD, Japan), AgNO 3 (99.9999\% purity, Aldrich, Japan), $\mathrm{HAuCl}_{4} \cdot 3 \mathrm{H}_{2} \mathrm{O}$ (Nacalai Tesque Inc., Japan) spermine (N,N'-bis(3-aminopropyl)-1,4-diaminobutane, Nacalai Tesque Inc., Japan), poly-(L-lysine) hydrobromide, fluorescent dye DAPI (4'6-diamidine-2-phenyl indole) (Molecular Probes, USA), and sodium borohydride (Nacalai Tesque Inc., Japan) were used as received.

Methods. Fluorescence microscopic observations were performed using an Axiovert 135 TV microscope (Carl Zeiss, Germany) equipped with a $100^{\times}$oil-immersed lens. Fluorescent images were recorded using an EB-CCD camera and an Argus 10 image processor (Hamamatsu Photonics, Hamamatsu, Japan).

UV-Vis spectra were recorded on a Jasco U-550 UV/VIS spectrophotometer in $1.0 \times 0.2 \times 0.5 \mathrm{~cm}$ quartz microcells.

Transmission electron microscopy (TEM) observations were performed using a JEM-1200EX microscope (JEOL, Tokyo, Japan) at an acceleration voltage of 100-120 kV. We used 300-mesh carbon-coated grids at room temperature. Each grid was placed for 3 minutes on top of a $15 \mu \mathrm{L}$ droplet of DNA solution on a Parafilm sheet and the solution was blotted with filter paper before microscopic observation.

\section{Sample preparation.}

$\mathrm{NaBH}_{4}$ solution was prepared immediately before the experiment and used for no longer than 6 hours after preparation, during which time it was kept in a cold place. (Caution: $\mathrm{NaBH}_{4}$ in water slowly decomposes releasing gaseous $\mathrm{H}_{2}$. Be careful of open fire and excessive pressure.) Metallization was performed as follows. Appropriate amounts of buffer (when used), fluorescent dye and compaction agent were added to distilled water and mixed well. DNA was added to the resulting solution and mixed gently to avoid breaking long DNAs. Fluorescence microscopy (FM) observations were performed 15-30 minutes after the DNA solutions were prepared. In the metallization procedure, first, a solution of metal salt was added, the solution was gently mixed and the metal was reduced by adding $\mathrm{NaBH}_{4}$ and mixing. Color appeared in the solutions immediately and its intensity grew until it became constant for 10-15 minutes. 


\section{Results and Discussion.}

Metallization with silver. It has been established ${ }^{36}$ that the compaction of giant DNA by multications can be described in terms of a first-order phase transition of a semi-flexible DNA chain. A tetracation such as spermine is one of the most common compaction agents which induce the folding transition of DNA. To achieve real-time observation of the conformational transition of long DNA chains in solution with spermine, we performed single-molecule observations of DAPI-labeled T4 DNA $(57 \mu \mathrm{m})$ by real-time fluorescence microscopy $(\mathrm{FM})$. Fluorescent images of $10^{-6} \mathrm{M}$ T4 DNA solution (in nucleotides) at different concentrations of spermine are shown in Figure 1. At a lower concentration of spermine (up to $0.2 \mu \mathrm{M}$ ), all of the DNA molecules are observed in an unfolded coil state characterized by the large thermal fluctuation of DNA chain segments (Figure 1, A). When the concentration of spermine is increased to $0.4 \mu \mathrm{M}$, DNA molecules exhibit the coexistence of elongated coil and folded compact states, where compact DNAs exhibit significant translational Brownian motion without visible intramolecular fluctuations and show much more intense fluorescence than those in the coil state, (Figure 1, B). At $1.0 \mu \mathrm{M}$ of spermine, all of the DNAs are in the compact state (Figure 1, C). It has been confirmed that individual compact DNA molecules behave as charged colloidal particles; they do not fuse to each other even when they collide during Brownian motion. This means that single-molecule compaction can be realized by avoiding the "condensation" of several DNA molecules. For the quantitative characterization of DNA compaction with spermine monitored by FM, we measured the percentage of compacted DNA chains (Figure 1, C) in solution by changing the concentration of spermine, as shown in Figure 2. Although the profile of this transition in terms of the compact DNA fraction is continuous, it is important to emphasize that such compaction is an all-or-none phenomenon with respect to the conformation of individual DNA molecules, i.e. coils and globules are the only two conformations adopted by individual DNAs and these two conformations coexist at intermediate spermine concentrations. ${ }^{36}$ 
Next, we performed silver metallization of the spermine-pretreated DNA chains described above. The differences in the nature of the deposition of noble metal on a DNA template at different concentrations of spermine can be clearly followed even with the unaided eye. Silver nitrate (final concentration is $100 \mu \mathrm{M})$ and the reducing agent $\mathrm{NaBH}_{4}(40 \mu \mathrm{M})$ were subsequently added to each experimental sample and mixed. The molar ratio between silver nitrate and sodium borohydride was chosen to assure sufficiently fast kinetics of silver reduction and metallization of DNA. Several times excess of reduction agent over stoichiometric amount $\left(1\right.$ molecule of $\mathrm{NaBH}_{4}$ for 8 molecules of $\mathrm{AgNO}_{3}$ ) was found to be optimal. Under these conditions, color of solution was developed within few minutes and was stable at least during a day. After the addition of borohydride, the color of the solution changed and varied from yellow to pink. Photographs of cells with samples are shown in Figure 3. The color of the final solution was yellow at lower concentrations of spermine and pink at higher concentrations. As shown in Figure 3, the observed color change is highly cooperative and abrupt; the solution has an intermediate color within a narrow concentration range of spermine $(0.2-0.3 \mu \mathrm{M})$. The yellow color of silver solutions corresponds to the formation of silver nanoparticles of several to several tens of nanometers. The red shift in the color of the solution indicates that relatively larger nanoparticles of metal are formed. A similar optical property of solution has been observed in studies on compact DNA metallization which leads to the formation of silver nanorings as a result of metal deposition on a DNA toroidal condensate. ${ }^{37}$

The corresponding UV-Vis spectra of DNA solutions with different amounts of spermine after the same metallization procedure are also shown in Figure 3. Corresponding to the change in the color of the solution, the spectra of this system can be easily classified into three types according to the absorption profile. In the absence of spermine and at low spermine concentrations, a single peak is observed at a wavelength of about $400 \mathrm{~nm}$. This peak corresponds to nanoparticles formed on the unfolded DNA template. At an intermediate concentration of spermine (very narrow concentration range), we observed a broader peak at $400 \mathrm{~nm}$ with a shoulder at a longer wavelength. At higher concentrations of spermine, two peaks with approximately equal intensities were observed at 400 
and $500 \mathrm{~nm}$. A further increase in the spermine concentration (at least 10 times higher than the concentration for DNA compaction) and metallization had no effect on the two-peak spectra.

For illustration, two different types of DNA metallization depending on the DNA conformational state are shown in Figure 4. Metallization of unfolded DNA proceeds through the formation of metal nanoparticles on a DNA chain, while that of compact DNA chains proceeds in a different way. Since a DNA chain has a toroid morphology upon compaction, this characteristic shape determines the form of the spectra, where absorbance around $400 \mathrm{~nm}$ corresponds to the smaller radius of the silver "hoop" (30-40 nm, d1) and that around $500 \mathrm{~nm}$ corresponds to the outer larger radius (d2) of the nanoring (around 80-90 nm) (see Figure 3). This two-peak pattern in UV-Vis spectra has been previously described in reports on noble metal nanorods. ${ }^{38,39}$ The morphology of gold nanorods is characterized by two geometrical dimensions (length and diameter), which results in a two-peak UV-Vis spectral pattern corresponding to the smaller and larger dimensions in the nanorod. ${ }^{38}$ Single nanoparticles, formed as a byproduct during reduction, were found to contribute somewhat to the intensity of the peak at $400 \mathrm{~nm}$. The ratio of these two absorbance peaks varies depending on the experimental conditions. For example, if there is a large excess of silver in solution compared to the concentration of DNA toroidal templates, a significant amount of free silver nanoparticles is formed together with the metallization of DNA, which are not deposited on DNA templates. In this case, the absorption peak at $400 \mathrm{~nm}$ is more intense. The deposition of silver metal on DNA condensate in the form of a ring is sensitive to a variety of experimental conditions including the concentrations of all of the components, the order and method of mixing, the temperature of the solution etc. However, under these various conditions, spectral changes properly indicate the transition point and reflect the shape asymmetry of the silver nanostructure. Corresponding transmission microscopy micrographs of metallized DNA condensates are presented in Figure 5 A and B.

To compare the concentration regime of the DNA folding transition from the coil to compact state (Figure 2) with optical changes after metallization with silver, the latter is presented in Figure 6 as the ratio of the absorbance intensities at 400 and $500 \mathrm{~nm}$ obtained by UV spectroscopic measurements. This ratio of 400 and $500 \mathrm{~nm}$ was chosen since it clearly illustrates the drastic change 
in silver nanostructure spectra. Comparison of Figures 2 and 6 makes it clear that changes in UV spectra correspond well to the original changes in the DNA conformation observed by single-molecule fluorescence microscopy. Therefore, the observed phenomenon clearly shows that monitoring of the manner of silver deposition on DNA can provide information about the DNA conformational state and is useful for determining the DNA binder concentration at which the conformational transition in a biopolymer occurs. It is to be noted that, although silver ions are cationic chemicals, compaction of DNA by silver nitrate itself does not occur even at millimolar concentrations (data not shown) in accordance with earlier theoretical predictions for monocations. ${ }^{40}$ Therefore, the influence of silver ions on DNA conformational transition point is considered to be negligible.

Metallization with gold. To obtain further insight into the metallization of DNA, we performed metallization with gold. For this metallization, we used $\mathrm{HAuCl}_{4}$ solution as a source of $\mathrm{Au}$ and the same reducing agent as with silver metallization, $\mathrm{NaBH}_{4}$, but with a somewhat higher ratio in comparison to silver to accelerate the reduction kinetics. The following experiments were performed in essentially the same manner as described for DNA metallization with silver. Figure 7 shows the color change in DNA solutions containing different concentrations of spermine after metallization with gold. UV-Vis absorbance of golden nanoparticles is located at longer wavelengths in comparison to that of nanoparticles of silver, and the initial solution containing unfolded DNA metallized by gold is colored pink and shows an absorbance maximum at about $520 \mathrm{~nm}$. This result suggests the formation of golden nanoparticles that measure about $10 \mathrm{~nm} .^{41}$ In contrast to the results with silver, a change in solution color is observed even at low concentrations of spermine; the absorbance shifts toward longer wavelengths accompanied by the color change from purple toward violet. This change in color reflects a difference in the size of gold nanoparticles formed after DNA metallization at different concentrations of spermine or the aggregation of nanoparticles. Whereas, the metallization of compact DNA with gold gave a solution with a faint blue-gray color.

Although the nature of the change in solution color is different between silver and gold, the point of the DNA conformational transition can be easily followed in both cases: after the compact DNA 
conformation appeared, the color of the solution did not change. Corresponding UV-Vis spectra are shown in Figure 7. When DNA is in a coil state, after gold metallization UV-Vis absorbance spectra undergo a red shift from $522 \mathrm{~nm}$ (curve 1 in Figure 7) to $537 \mathrm{~nm}$ (curve 2) and then to $543 \mathrm{~nm}$ (curve 3), while the absorbance intensity remains almost constant. This shift of the absorbance maximum suggests that the addition of spermine to DNA solution leads to the formation of larger particles. The abrupt change in the shape of the spectra accompanied by the appearance of compact DNA can be clearly seen, similar to the results with silver metallization. After the transition, the shape of the spectra remains almost unchanged, with a broad absorbance region on $600-900 \mathrm{~nm}$ and a weakly pronounced peak at $530 \mathrm{~nm}$, which remains constant with increasing amounts of spermine. In the case of gold, the characteristic clear two-peak spectra do not appear, in contrast to the spectral changes that accompany metallization with silver.

Using transmission microscopy, we found that the first steps in gold deposition on an unfolded DNA chain are very similar to those of silver deposition; nanoparticles or metallized regions are observed on DNA, as shown in Figure 5. At a higher concentration of spermine in solutions of DNA, structures containing compact units that measure about $100 \mathrm{~nm}$ with an unfolded DNA chain in the same structures are observed (Figure $5 \mathrm{C}$ and D). We expect that such structures may appear as a result of the metallization of DNA loops formed as a kinetic step in DNA compaction by multications. At high concentrations of spermine, compact nanostructures which are assigned to metallized DNA toroids were observed, as shown in Figure 5 E-F. Such metallized toroids are markedly different from smooth silver nanorings and contain many discrete nanoparticle units on the surface. Golden nanorings were frequently found to be aggregated during TEM observations, which can explain the absence of a clear peak at a wavelength corresponding to the larger diameter of a nanoring. It is expected that such aggregation may be avoided by choosing suitable experimental conditions, and the formation of a smooth golden ring may become possible. Our results suggest that metal deposition in the form of a smooth layer or in the form of particles depends on the stability of the corresponding nanoparticles of larger sizes. Thus, when large nanoparticles are generated upon reduction under the same experimental conditions but without DNA seeds in solution, the deposition 
of a noble metal on a DNA toroid proceeds in the form of a smooth metal shell as was actually observed for silver metallization. On the other hand, if small metal nanoparticles are generated under the same conditions in solution without DNA, the metal is deposited on a toroid surface in the form of nanoparticles, as we found for gold. Systematic analyses of the relationship between the experimental conditions and the morphology of the final nanostructures are now underway. Metallization with gold is similar to that with silver due to the abrupt nature of the transition and the fact that there are almost no spectral changes after the structural transition of DNA. Thus, the DNA conformational transition can be easily monitored by following the spectral change. Here, it is to be noted that, without metallization, the folding transition of giant DNA molecules exhibits essentially no spectral change in usual UV-VIS measurements. Figure 8 shows the change in the ratio of the absorbance intensities at $500 \mathrm{~nm}$ and $750 \mathrm{~nm}$ as a function of the spermine concentration. The change in the shape of the spectrum in terms of the intensity ratio closely resembles that of the curve for silver in Figure 6. Therefore, regardless of the nature of the noble metal, the compaction of DNA into toroids and successive metallization is clearly indicated by the shape of UV absorption spectra, where silver is probably more useful for detecting the morphology of compact DNA.

DNA compaction with a cationic polymer and metallization. The chemical nature of the DNA condensing agent influences the mechanism of DNA compaction, the morphology of the final condensates and, in turn, the resulting metal nanostructure after DNA metallization. DNA condensates do not always have a toroidal morphology. In fact, stronger compaction agents such as polycations disfavor the formation of DNA toroids, and DNA condensates usually have a globular (spherical) morphology. ${ }^{42}$ To clarify the formation of a non-toroidal condensate, we studied the metallization of DNA after interaction with the typical polycation poly-(L-lysine), which has a molecular weight of 30,000. Fluorescence microscopy images in Figure 9 and the evolution of DNA length in Figure 10 show that, in contrast to DNA compaction with spermine, the compaction of DNA molecules by a polycation is gradual and observed by fluorescence microscopy as a shrinking of DNA coils and the formation of compact globules at concentrations near the point of 1:1 charge equivalence between the negatively charged phosphates of DNA and the positively charged 
aminogroups of polylysine. At a certain concentration (Figure 9 D), the fluorescence of single DNA molecules was strongly quenched, probably due to the release of fluorescent dye from DNA upon compaction. After the addition of an excess amount of polylysine, DNA globules became swollen and the fluorescence intensity from such swollen globules increased strongly. These changes indicate the beginning of the reverse process of compact DNA unfolding in the presence of excess polycation caused by overcharging of the DNA chain by the excess polycation.

We performed the metallization of DNA solution with different amounts of polylysine using essentially the same procedure as was described for DNA-spermine metallization with silver. The changes in the color of the solution together with corresponding UV spectra are shown in Figure 11. When DNA is in the unfolded form, the shape of the spectra changed only slightly until compaction. The spectra intensity increases and then decreases, and the maximum absorbance wavelength decreases, indicating that smaller particles are formed at higher percentages of DNA complexation with polycation. The point of complete DNA compaction into globules, or the disappearance of the unfolded coil state in the population, is clearly indicated by a change in the color of the solution from yellow to gray. This color change is observed by UV-spectroscopy as a disappearance of the $400 \mathrm{~nm}$ peak and the appearance of a broad absorption band at longer wavelengths. Interestingly, with an increase in the poly-(L-lysine) content above the concentration of DNA collapse, a reverse tendency was observed. The solution turned yellow and an intense absorbance peak was again observed at about $400 \mathrm{~nm}$. The appearance of this peak indicates the formation of nanoparticles and can be ascribed to the unfolding of DNA in the presence of excess poly(L-lysine) chains in solution which acts as a template for the formation of nanoparticles. After the reverse change in the color of the solution, the absorbance maximum is at a longer wavelength (about $410 \mathrm{~nm}$ ) than that was observed for earlier stages of DNA-polycation interaction at charge ratios below one. The observed changes indicate that in the case of DNA compaction by a polycation, the change in the conformation of DNA can also be easily followed by visual (colorimetric) and spectroscopic changes after metallization with a noble metal, where the nature of the condensing agent affects the color-evolution scenario. Typical products of DNA-polylysine complex metallization are shown in 
Figure $5 \mathrm{G}$ and $\mathrm{H}$. In contrast to the DNA toroidal nanostructures formed as a result DNA compaction with spermine and metallization, the final products of DNA compaction with a polycation and metallization are metal particles with an average size of about 150-200 nm, while no ring structures were observed.

Discussion. In the $21^{\text {st }}$ century, the development of analytical techniques for biochemical and biomedical applications based on the advantages of new noble metal nanostructures has progressed dramatically. ${ }^{43}$ Many powerful new experimental techniques have been described, including single-molecule microscopic observations, colorimetric screening of DNA binders, "bar-code-based" detection of proteins and oligonucleotides, etc. On the other hand, the analytical detection of higher-order structures formed by biopolymers has not yet been developed. It may be clear that development of the methodology for the detection of DNA or protein conformation is important in biomedical applications, such as DNA compaction for gene delivery or protein folding without denaturation. In the current study, we have shown that the conformation of sufficiently long DNA such as T4 DNA determines the nature of the deposition of noble metals on a DNA polymeric template, which can be used for the analytical detection of biopolymer conformation. The fine morphology of the resulting metal nanostructures is controlled by various parameters such as the chemical structure of the DNA compaction agent, type of metal, etc. Excluding the scenario of DNA chain compaction, the important feature of DNA-conformation probing by metallization is the clear correspondence between the changes in the absorbance of the metal nanostructure and the conformation of the DNA polymeric chain.

Comparison of the optical properties of the nanostructures formed as a result of DNA scaffold metallization by direct bulk observation of the conformational behavior of single DNA chains clarified that this metallization methodology can be used to probe phase transitions of long-chain biopolymers. In particular, with this metallization approach it is possible to evaluate (i) the critical concentration of condensing agent needed to induce a conformational transition in biopolymers, (ii) the nature of this transition, (iii) the dimension of the final condensate, and (iv) the morphology of the compact biopolymer condensate. The noble metals silver and gold are suitable candidates for this 
purpose. We expect that other heavy metals such as platinum, copper, etc. will also be useful for the metallization and analytical detection of biopolymer conformation. With this simple method based on polymer chain metallization, the conformational state of a biopolymer at concentrations as low as $10^{-6} \mathrm{M}$ can be detected simply by monitoring the changes in the color of the sample solution. With a decrease in the DNA chain length, the detection limit of our procedure in terms of the DNA concentration can be further enhanced as a result of the presence of more DNA "seeds" and an increased percentage of metal deposited on the DNA template compared to the formation of free nanoparticles in solution.

For measurement of transition point between elongated and compact states of DNA, it is not necessary to know the exact concentration of DNA in sample, because the drastic change in spectral properties of formed metal nanostructures upon transition is clearly recognized, and even high concentration of silver is not the obstacle for determination of DNA transition point in a broad range of concentrations. On the other hand, when one attempts to measure DNA conformation at a single point, special care should be taken while interpreting the observed spectra if DNA concentration is unknown. While peak at $500 \mathrm{~nm}$ (the case of silver) unambiguously indicates appearance of compact DNA, it might be difficult to distinguish fully compacted DNA state from the coexistence in situation, for instance, where an excess of nanoparticles exists. The control experiment with addition of a portion of known condensing agent to the solution and metallization should give an answer if DNA is completely compacted (no spectral changes) of not (decrease of $400 \mathrm{~nm}$ peak).

Although noble metals are well known to be able to complex with various ligands, their compositions in solution can be varied over a broad range, while the correspondence between the changes in the conformation of DNA and UV spectral changes is preserved. However, in salt-free solutions or at very low salt concentrations (up to about $10^{-3} \mathrm{M}$ ), the addition of a noble metal can significantly influence DNA rigidity and its electrostatic properties, and, as a result, the changes in UV spectra may not correspond exactly to the actual transition concentrations. The development of more robust procedures for screening DNA conformation is currently in progress. 
Conclusions. Our results showed that the manner of noble metal deposition on a long DNA chain upon reduction is sensitively dependent on the DNA chain conformation. This difference and the outstanding optical properties of noble metal nanostructures provide a variety of means to monitor conformational changes in biopolymers in highly dilute solutions by colorimetric and spectral methods and even with the unaided eye. This method of metallization may be useful for detecting the conformational state of any sufficiently long macromolecules and for probing important conformational changes such as DNA compaction and protein folding using a high-throughput colorimetric method. The rapid and simple detection of polymer conformation is a prospective tool for the analysis of large libraries of chemicals involved in the regulation of DNA or protein conformation. Furthermore, this method involving metal deposition is also sensitive to the shape and dimension of the compact biopolymer chain and can potentially be useful for probing the asymmetry of compact DNA or protein structures with a submicron resolution. 

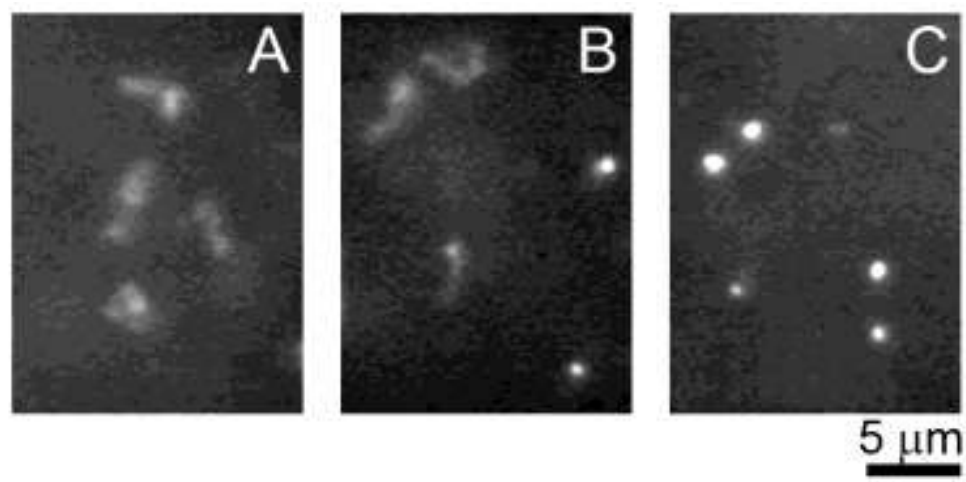

Figure 1. Fluorescence microscopic observations of DNA molecules in bulk aqueous solution at different spermine(4+) concentrations. Concentrations of spermine are $0(\mathbf{A}), 0.4(\mathbf{B})$, and $2.5 \mu \mathrm{M}$ (C), respectively. Coil (A), coil-globule coexistence (B), and globule (C) states. The appearance of the coexistence state implies that the transition is all-or-none at the level of individual DNA molecules. 


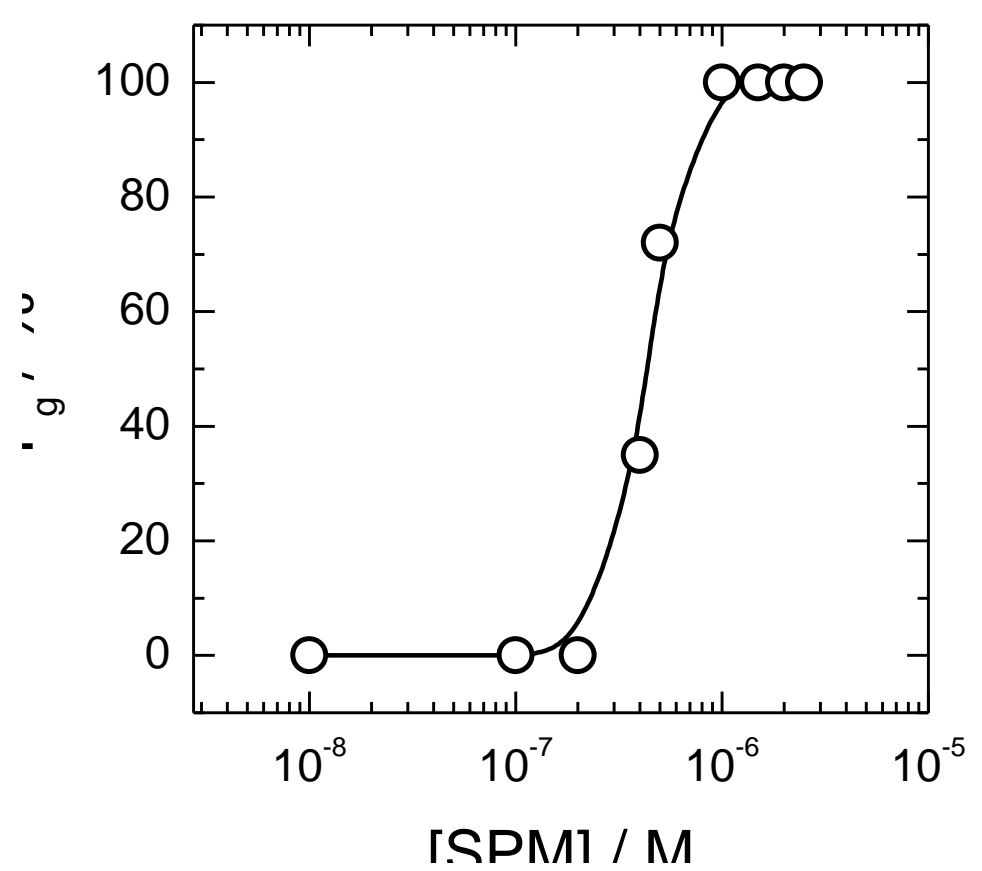

Figure 2. Fraction of compact T4 DNA molecules $(1 \mu \mathrm{M})$ depending on the spermine concentration as determined by fluorescence microscopy analysis of the DNA conformation for at least 100 DNA molecules at each concentration. 

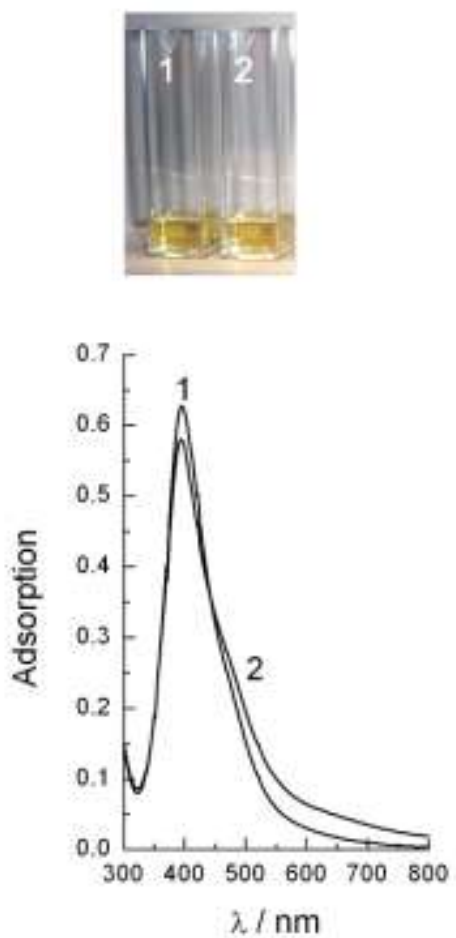
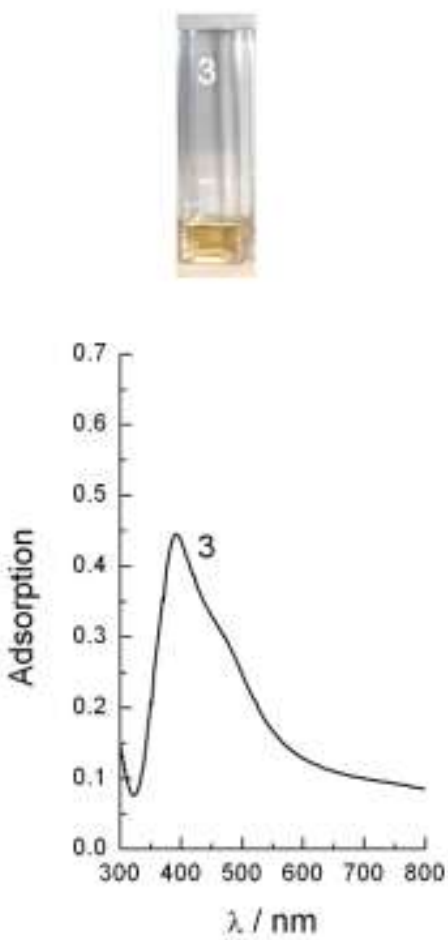
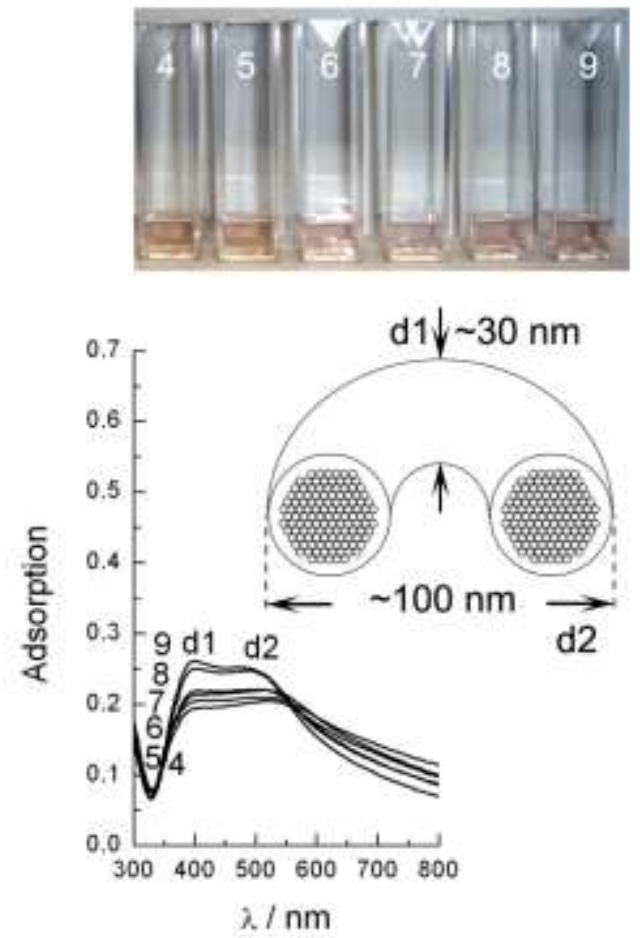

Figure 3. Photographic images and corresponding UV-Vis spectra of T4 DNA $(1 \mu \mathrm{M})$ metallized with $100 \mu \mathrm{M} \mathrm{AgNO}_{3}$ and $40 \mu \mathrm{M}$ of $\mathrm{NaBH}_{4}$ at different spermine concentrations (from 1 to 9: $0,0.1$, $0.2,0.4,0.5,1,1.5,2.0$, and $2.5 \mu \mathrm{M}$, respectively). 


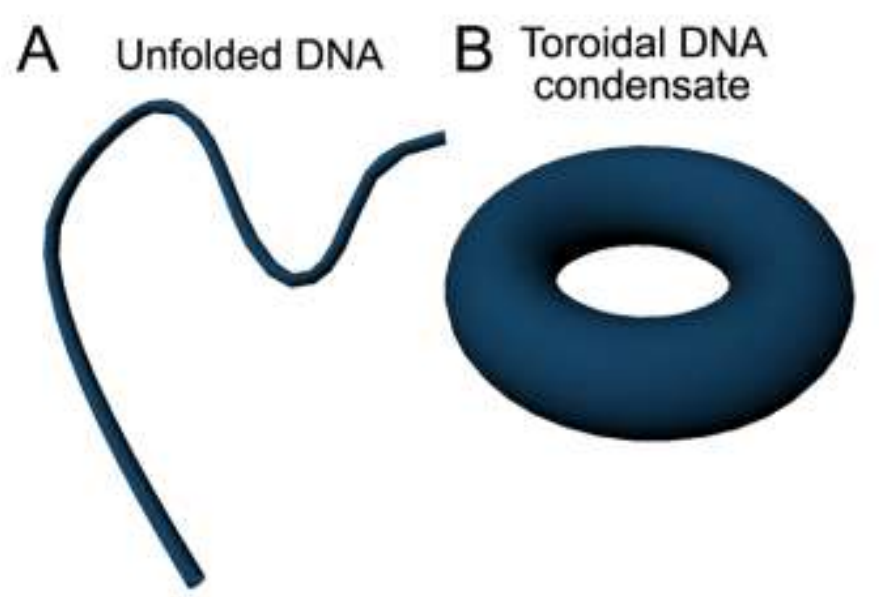

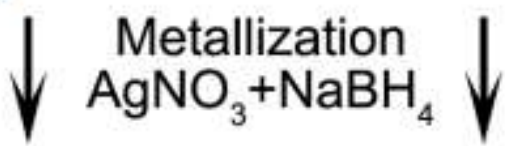

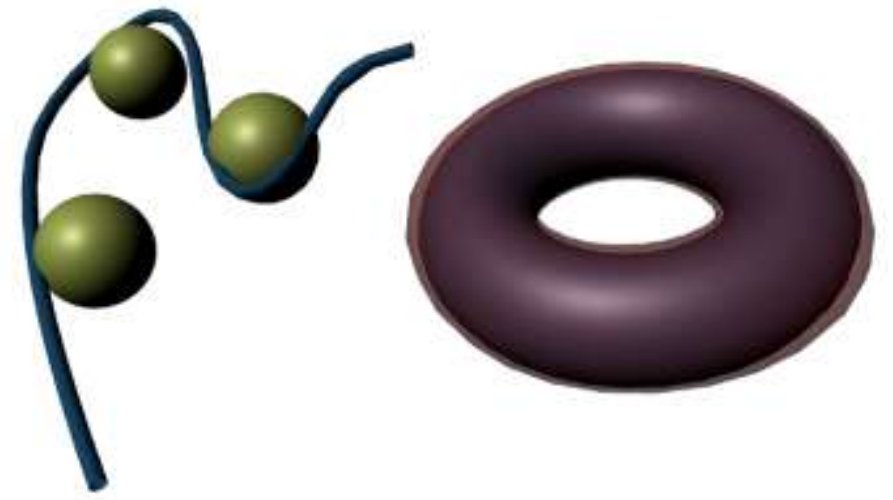

Figure 4. Schematic representation of silver deposition on unfolded (A) and compact (B) DNA templates. 


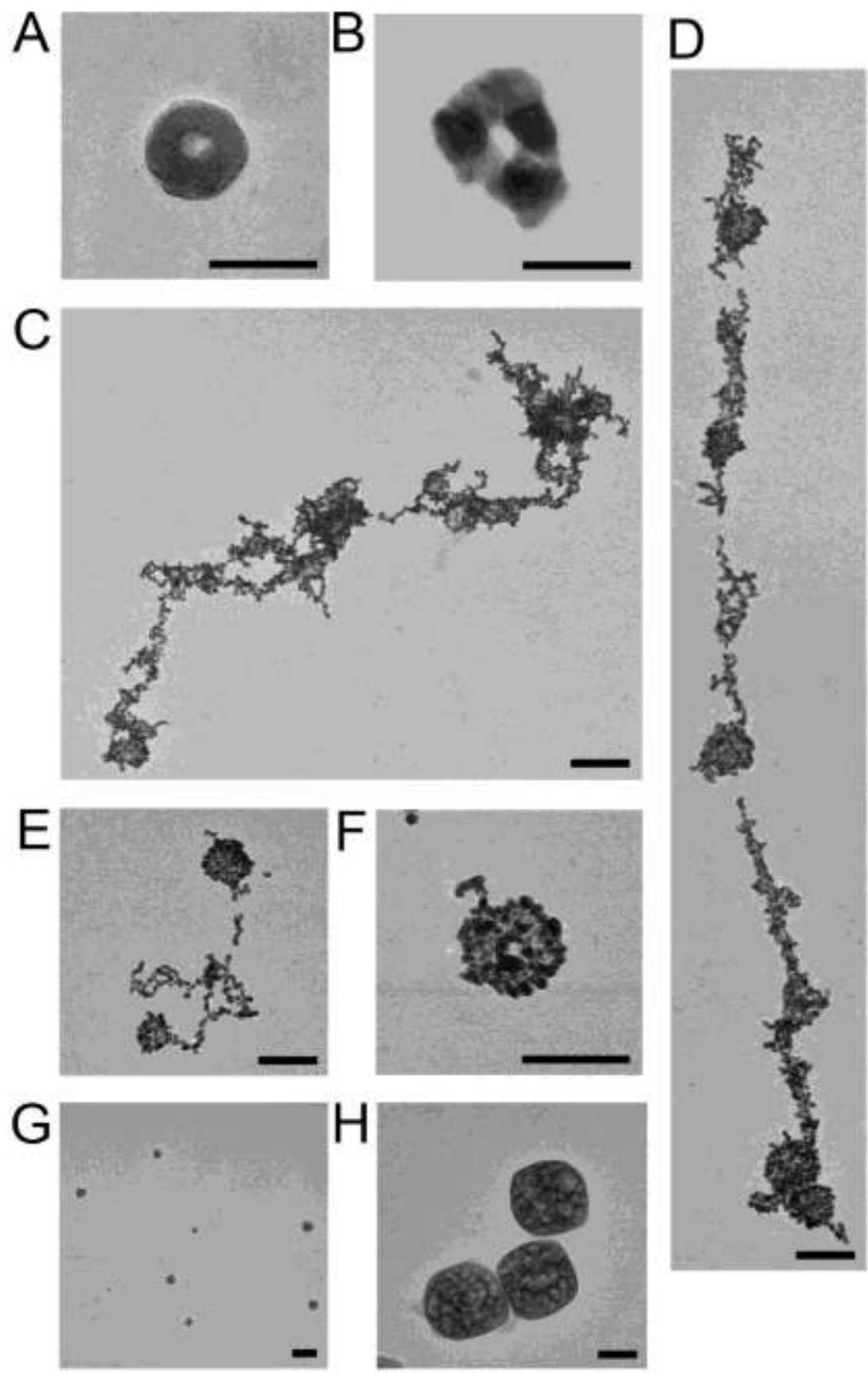

Figure 5. Transmission electron microscopic images of T4 DNA $\left(10^{-6} \mathrm{M}\right)$ compacted by multication and polyelectrolyte at different stages of DNA compaction. A and B. T4 DNA compacted by spermine $(20 \mu \mathrm{M})$ and metallized by $\mathrm{AgNO}_{3}(100 \mu \mathrm{M})$ with reduction by $\mathrm{NaBH}_{4}(100 \mu \mathrm{M})$. C. T4 DNA metallized with $\mathrm{HAuCl}_{4}(40 \mu \mathrm{M})$ and $\mathrm{NaBH}_{4}(40 \mu \mathrm{M})$. D, E, F. T4 DNA compacted by spermine $(5 \mu \mathrm{M})$ and metallized by $\mathrm{HAuCl}_{4}(40 \mu \mathrm{M})$ with reduction by $\mathrm{NaBH}_{4}(40 \mu \mathrm{M})$. G, H. T4 DNA compacted by poly(L-lysine) $\left(10^{-6} \mathrm{M}\right)$ and metallized by $\mathrm{AgNO}_{3}(40 \mu \mathrm{M})$ with reduction by $\mathrm{NaBH}_{4}(20 \mu \mathrm{M})$. Scale bar is $100 \mathrm{~nm}$ except for $\mathrm{G}(500 \mathrm{~nm})$. 


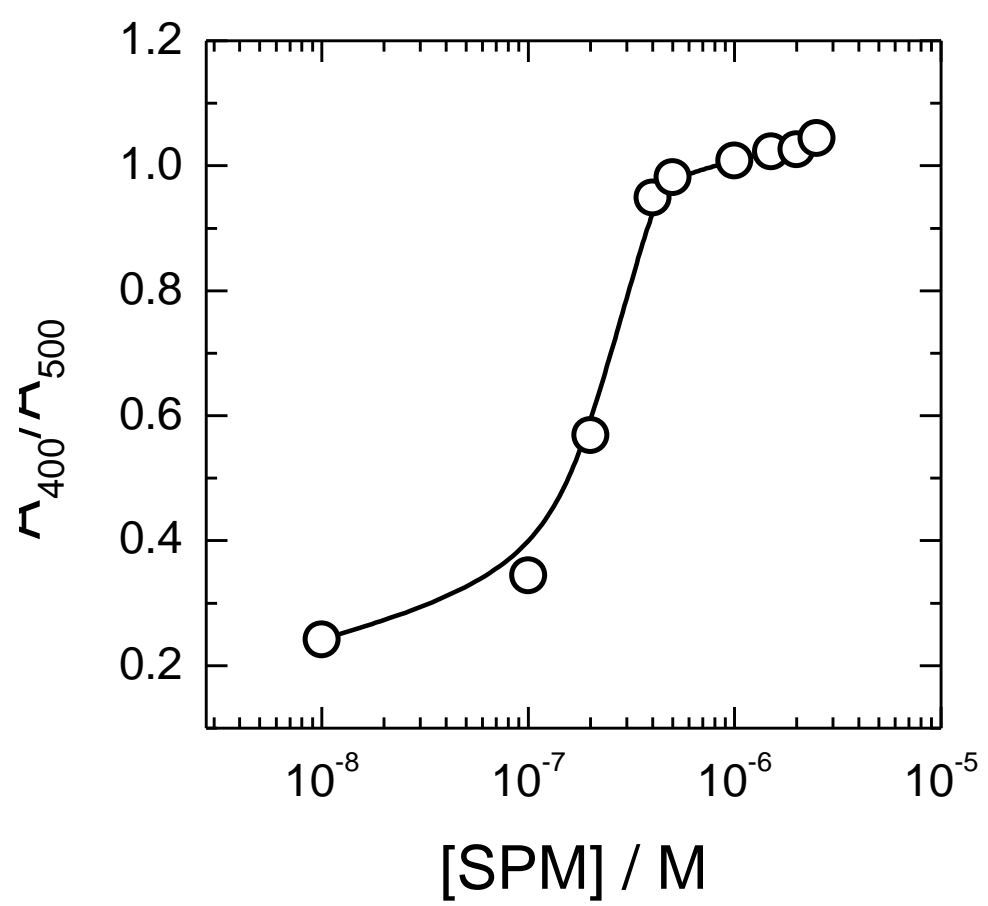

Figure 6. Ratio of the absorbance maximums at $400 \mathrm{~nm}$ and 500 depending on T4 DNA metallized with $100 \mu \mathrm{M} \mathrm{AgNO}_{3}$ and $40 \mu \mathrm{M}$ of $\mathrm{NaBH}_{4}$ at different spermine(4+) concentrations. 

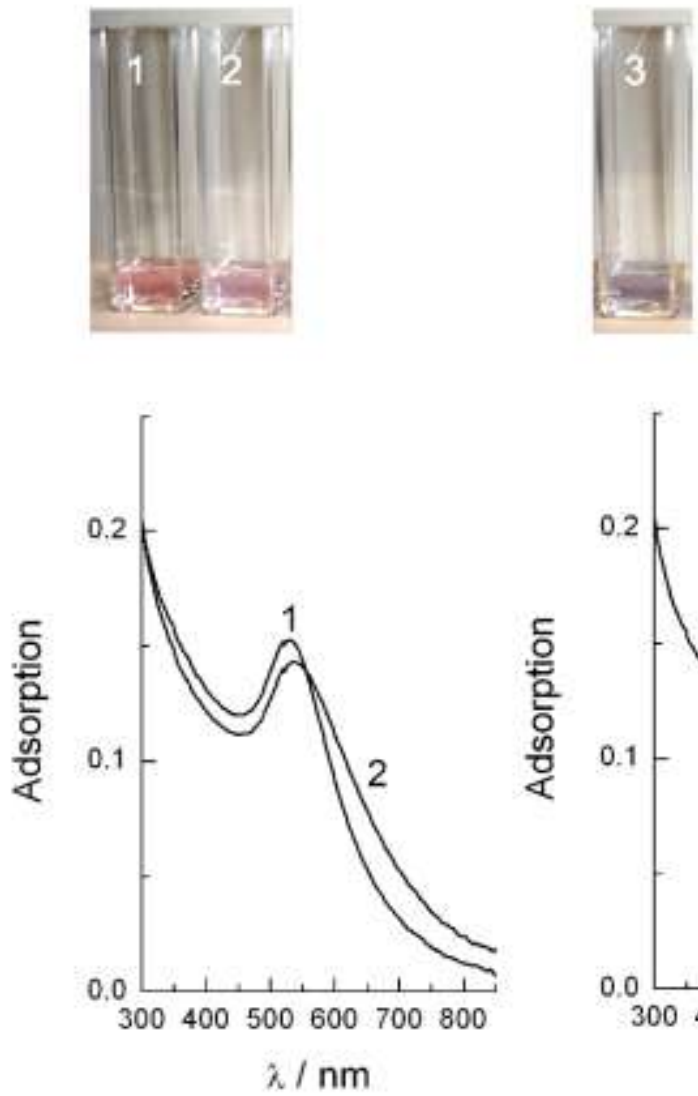
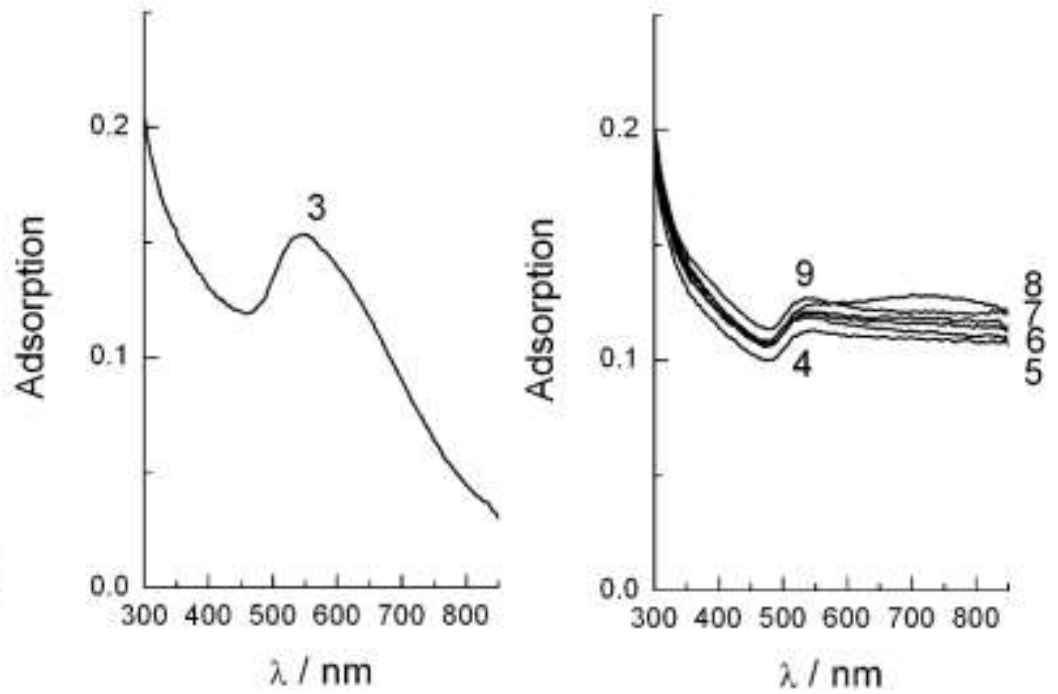

Figure 7. Photographic images and corresponding UV-Vis spectra of T4 DNA $(1 \mu \mathrm{M})$ metallized with $100 \mathrm{M} \mathrm{HAuCl}_{4}$ and $100 \mathrm{M}$ of $\mathrm{NaBH}_{4}$ at different concentrations of spermine $(1-0,2-0.1,3-$ $0.2,4-0.4,5-0.5,6-1.0,7-1.5,8-2.0$ and $9-2.5 \mu \mathrm{M})$. 


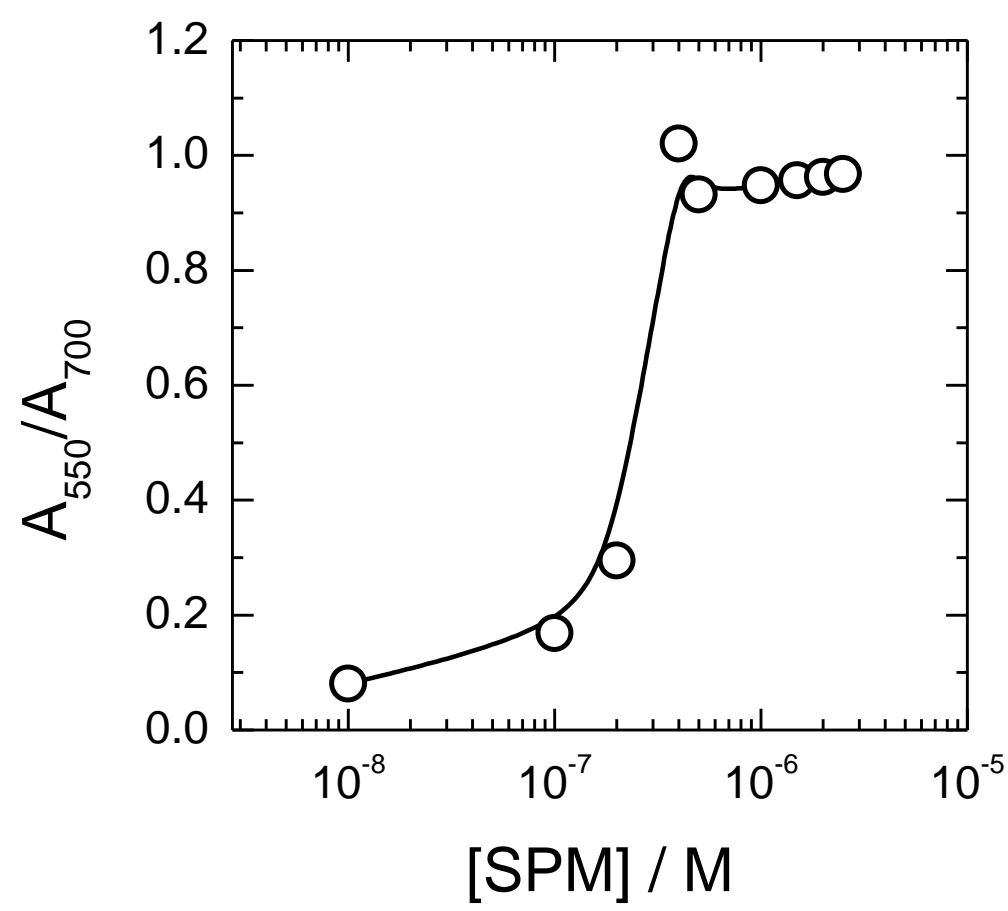

Figure 8. Ratio of the absorbance maximums at $550 \mathrm{~nm}$ and $700 \mathrm{~nm}$ depending on the concentration of spermine in $1 \mathrm{mM}$ Tris-HCl T4 DNA solution after metallization with $100 \mu \mathrm{M} \mathrm{HAuCl}_{4}$ and 100 $\mu \mathrm{M}$ of $\mathrm{NaBH}_{4}$. 

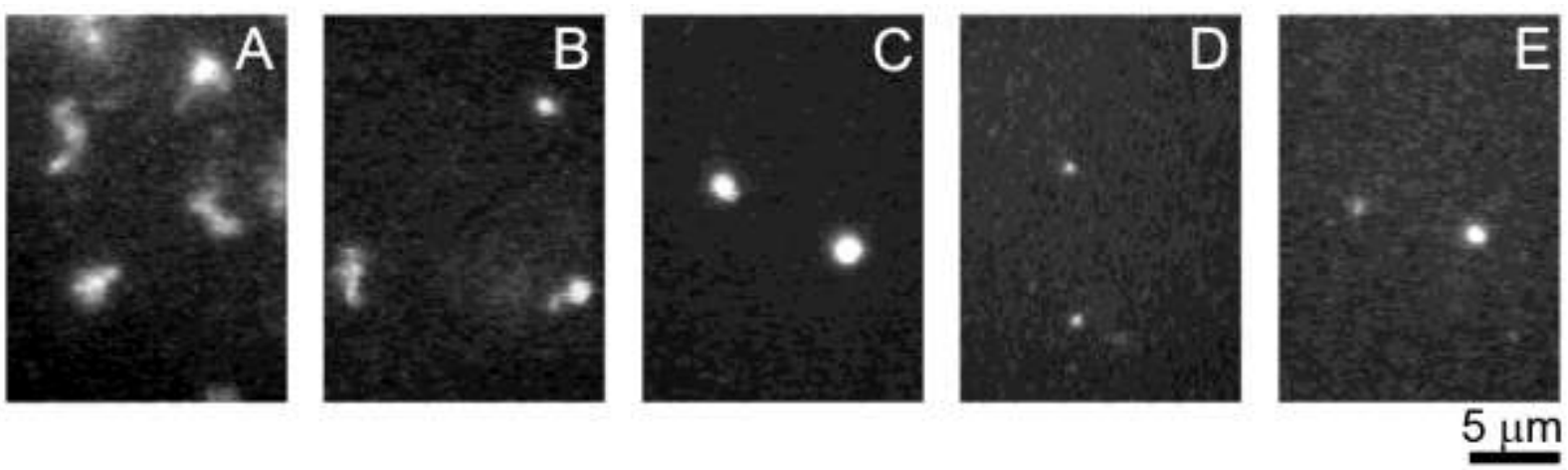

Figure 9. Fluorescence microscopic observations of the evolution of the conformational state of single-molecule DNA through interaction with poly(L-lysine). Fluorescent micrographs of DAPI-labeled T4 DNA solution $(1 \mu \mathrm{M})$ at poly-(L-lysine) a concentrations of $0(\mathbf{A}), 0.4(\mathbf{B}), 0.8(\mathbf{C})$, 1.4 (D) and $3 \mu \mathrm{M}(\mathbf{E})$, respectively. Coil. (A), shrunken coil (B, C), globule (D), and globule coexisting with swollen globules (E). 


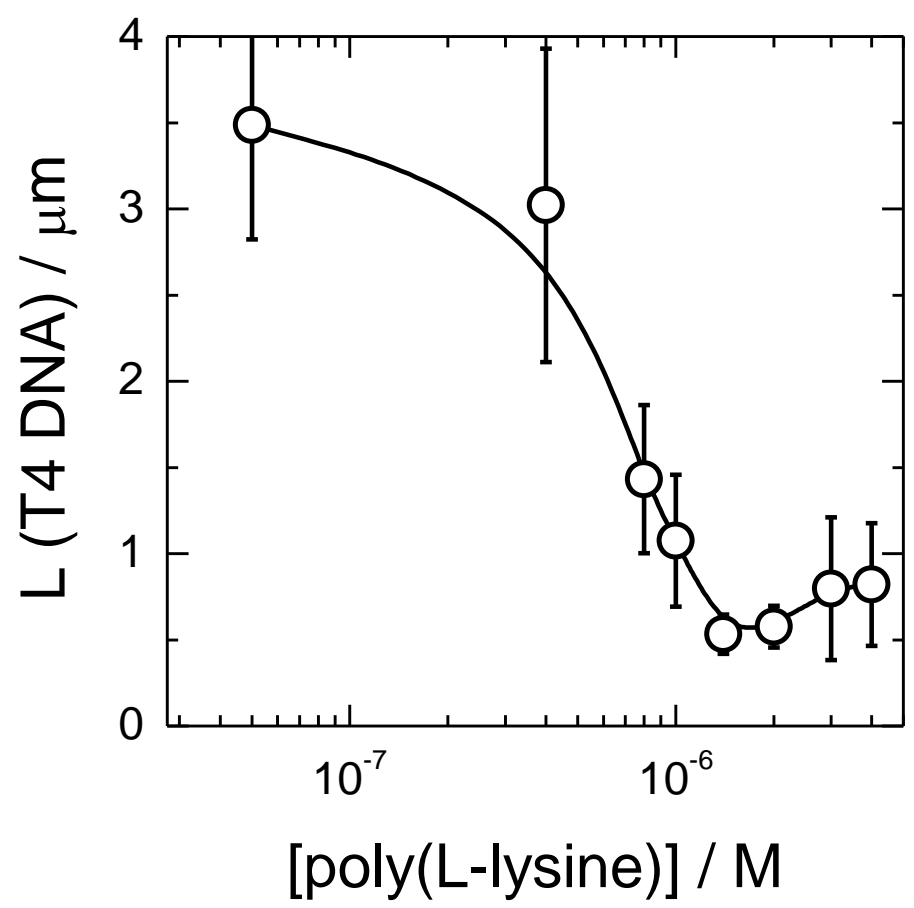

Figure 10. Change in the long-axis length of T4 DNA $(1 \mu \mathrm{M})$ in $1 \mathrm{mM}$ Tris- $\mathrm{HCl}(\mathrm{pH}=7.4)$ solutions at different concentrations of poly-(L-lysine) shown as the dependence of the average long-axis length of T4 DNA molecules on the concentration of poly-(L-lysine). For this analysis, 50-100 molecules were measured at each poly-(L-lysine) concentration. Statistical error is given as the standard deviation. 

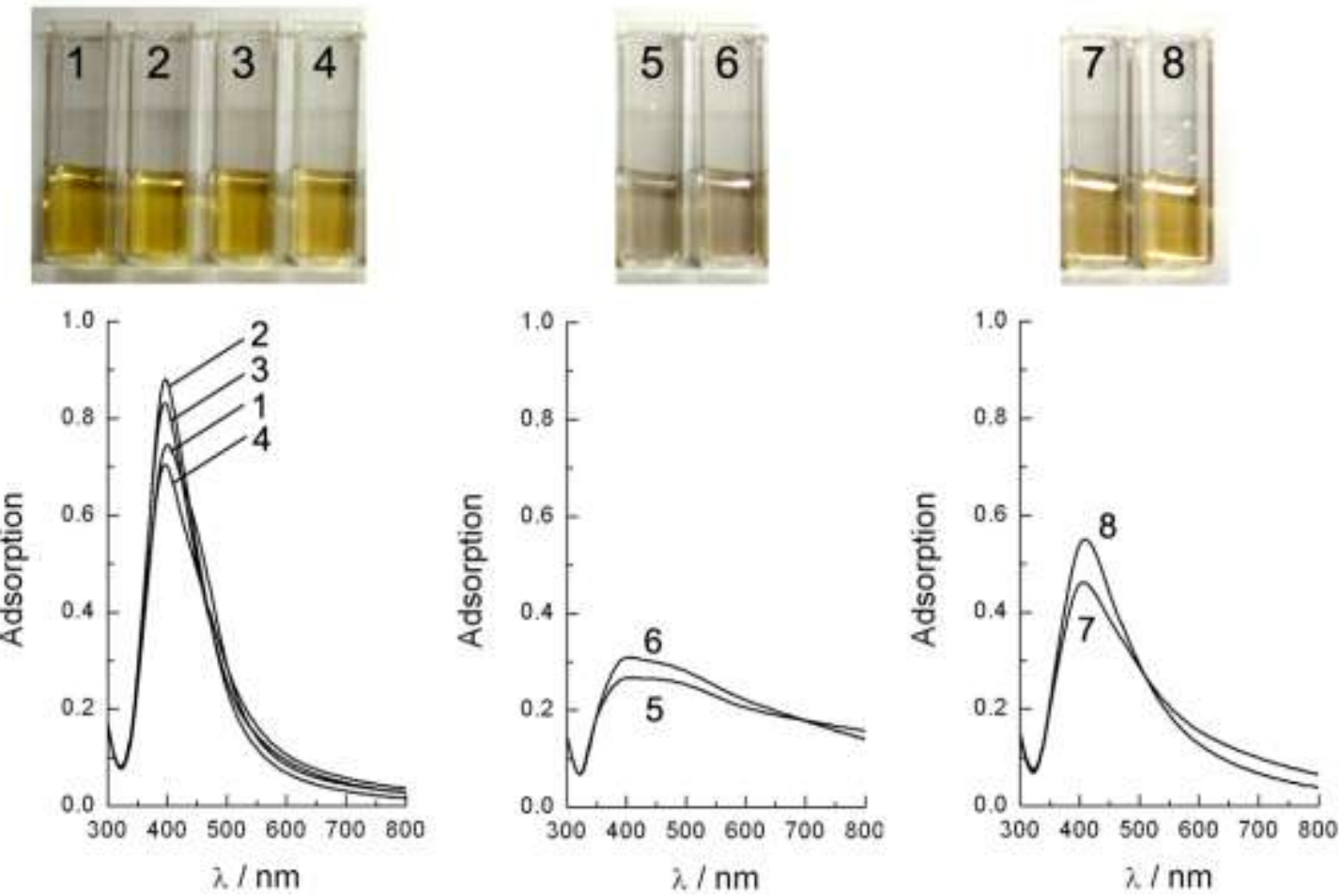

Figure 11. Photographic images and corresponding UV-Vis spectra of solutions containing T4 DNA $(1 \mu \mathrm{M})$ in $1 \mathrm{mM}$ Tris- $\mathrm{HCl}$ and different amount of spermine (from 1 to 8: 0, 0.4, 0.8, 1, 1.4, 2,3 and $4 \mu \mathrm{M}$, respectively) subjected to metallization by the addition of $100 \mathrm{M} \mathrm{AgNO}_{3}$ and $40 \mathrm{M}$ of $\mathrm{NaBH}_{4}$. 


\section{References}

1. Sun Y., Xia Y., Science 2002, 298, 2176-2179.

2. Corbierre K. M., Cameron S. N., Lennox R. B., Langmuir 2004, 20, 2867-2873.

3. Hussain I., Graham S., Wang Z., Tan B., Sherrington C. D., Rannard P. S., Cooper I. A., Brust M., J. Am. Chem. Soc. 2005, 127, 16398-16399.

4. Pérignon N., Mingotaud A-F., Marty J-D., Rico-Lattes I., Mingotaud C., Chem. Mater. 2004, 16, 4856-4858.

5. Gao J., Fu J., Lin C., Lin J., Han Y., Yu X., Pan C., Langmuir 2004, 20, 9775-9779.

6. Mirkin C. A., Letsinger R. L., Mucic R. C., Storhoff J. J., Nature 1996, 382, 607-609.

7. Storhoff J. J., Mirkin C. A., Chem. Rev. 1999, 99, 1849-1862.

8. Claridge S. A., Goh S. L., Fréchet J. M. J., Williams S. C., Micheel C. M., Alivisatos A. P., Chem. Mater. 2005, 17, 1628-1635.

9. Shaikh K. A., Ryu K. S., Goluch E. D., Nam J., Liu J., Thaxton C. S., Thomas N., Barron A. E., Lu Y., Mirkin C. A., Liu C.. Proc. Natl. Acad. Sci. USA 2005, 102(28), 9745-9750.

10. Nam J., Thaxton C. S., Mirkin C. A., Science 2003, 301(5641), 1884-1886.

11. Han M. S., Lytton-Jean A. K. R., Oh B-K., Heo J., Mirkin C. A., Angew. Chem. Intl. Ed. 2006, $45,1807-1810$.

12. Schmid G. (Ed.) Nanoparticles: From Theory to Applications, VCH, Weinheim, 2004.

13. Braun E., Eichen Y., Sivan U., Ben-Yoseph G., Nature 1998, 391, 775-778.

14. Kiriy A., Minko S., Gorodyska G., Stamm M., Nano Lett. 2002, 2, 881-885.

15. Minko S., Kiriy A., Gorodyska G., Stamm M., J. Am. Chem. Soc. 2002, 124, 10192-10197.

16. Patolsky F., Weizmann Y., Lioubashevski O., Willner I., Angew. Chem. Int. Ed. 2002, 41, 2323-2327.

17. Wang G., Murray R. W., Nano Lett. 2004, 4, 95-101.

18. Nyamjav D., Kinsella J. M., Ivanisevic A., Appl. Phys. Lett. 2005, 86, 093107.

19. Niemeyer C. M., Simon U., Eur. J. Inorg. Chem. 2005, 18, 3641-3655. 
20. Becerril H. A., Stoltenberg R. M., Monson C. F., Woolley A. T., Mater. Chem. 2004, 14, 611-616.

21. Ford W. E., Harnack O., Yasuda A., Wessels J. M., Adv. Mater. 2001, 13, 1793-1797.

22. Richter J., Mertig M., Pompe W., Mönch I., Schackert H. K., Appl. Phys. Lett. 2001, 78, 536-538.

23. Braun G., Inagaki K., Estabrook R. A., Wood D. K., Levy E., Cleland A. N., Strouse G. F., Reich N. O., Langmuir 2005, 21, 10699-10701.

24. Mertig M., Ciacchi L. C., Seidel R., Pompe W., Vita A. D., Nano Lett., 2002, 2, 841-844.

25. Nyamjav D., Kinsella J. M., Ivanisevic A., Appl. Phys. Lett. 2005, 86, 093107.

26. Nakao H., Shiigi H., Yamamoto Y., Tokonami S., Nagaoka T., Sugiyama S., Ohtani T., Nano Lett. 2003, 3, 1391-1394.

27. Karen K., Berman R., Braun E., Nano Lett. 2004, 4, 323-326.

28. Monson C. F., Wooley A. T., Nano Lett. 2003, 3, 359-363.

29. Xin H., Wooley A. T., J. Am. Chem. Soc. 2003, 125, 8710-8711.

30. Harnack O., Ford W. E., Yasuda A., Wessels J. M., Nano Lett. 2002, 2, 919-923.

31. Mertig M., Ciacchi L., Siedel R., Pompe W., Vita A. D., Nano Lett. 2002, 2, 841-844.

32. Ma Y., Zhang J., Zhang G., He H., J. Am. Chem. Soc. 2004, 126, 7097-7101.

33. Nyamjav D., Kinsella M. J., Ivanisevic A., Appl. Phys. Lett. 2005, 86, 093107.

34. Richter J., Seidel R., Kirsch R., Mertig M., Pompe W., Plaschke J., Schackert K. H., Adv. Mater. 2000, $12,507-510$.

35. Wei G., Zhou H., Liu Z., Song Y., Wang L., Sun L., Li Z., J. Phys. Chem. B 2005, 109, 8738-8743.

36. Yoshikawa K., Takahashi M., Vasilevskaya V. V., Khokhlov A. R., Phys. Rev. Lett. 1996, 76, 3029-3031.

37. Zinchenko A. A., Yoshikawa K., Baigl D., Adv. Mater. 2005, 17, 2820-2823.

38. Mohamed M. B., Volkov V., Link S., El-Sayed M. A., Chem. Phys. Lett. 2000, 317, 517-523.

39. Jana N. R., Gearheart L., Murphy C. J., J. Phys. Chem. B 2001, 105, 4065-4067. 
40. Wilson, R. W., Bloomfield, V. A. Biochemistry 1979, 18, 2192-2196

41. Storhoff J. J., Elghanian R., Mucic R. C., Mirkin C. A., Letsinger R. L., J. Am. Chem. Soc. 1998, 120, 1959-1964.

42. Perales J. C., Ferkol T., Beegen H., Ratnoff O. D., Hanson, R.W., Proc. Natl. Acad. Sci. USA 1994, 91, 4086-4090.

43. Rosi, N. L., Mirkin, C. A., Chem. Rev. 2005, 105(4), 1547-1562. 